\title{
Serum long acting thyroid stimulator protector in pregnancy complicated by Graves' disease
}

\author{
C A HARDISTY, D S MUNRO
}

\begin{abstract}
Activities of serum long acting thyroid stimulator protector were measured in a series of nine pregnancies in eight mothers who had Graves' disease, one of whom had been successfully treated by surgery. In all but two instances the activities tended to decline as pregnancy progressed. After delivery activities rose in three out of five patients in whom these had disappeared in pregnancy and, as this occurred, the patients relapsed. In the two patients whose activities did not decline thyrotoxicosis persisted throughout pregnancy and after delivery.

None of the nine babies in this study suffered from neonatal thyrotoxicosis because maternal activities of the thyroid stimulator protector, though high enough to induce Graves' disease in adults, were not above the threshold for the induction of thyroid overactivity in neonates.
\end{abstract}

\section{Introduction}

It is now widely accepted that the thyroid overactivity of Graves' disease is caused by circulating antibodies which stimulate the thyroid at or near the thyroid stimulating hormone receptor. Many different methods have been described for measuring these immunoglobulin activities, one of which is the measurement of serum long acting thyroid stimulator protector. ${ }^{1}$ Clinical studies show a close relation between the course of Graves' disease and activities of this factor in the serum. ${ }^{2}$

During pregnancy Graves' disease tends to remit, so that antithyroid drugs can almost invariably be reduced and sometimes even discontinued. ${ }^{3}$ The reason for this is unknown but may be related to changes in thyroid autoantibody values during pregnancy. A prolonged clinical prospective study on Graves' disease enabled us to measure serum long acting thyroid stimulator protector before, during, and after nine pregnancies in eight women.

\section{Patients and methods}

Eight women (mean age 26 years, range 24-31) were studied. Seven had Graves' disease requiring carbimazole, the mean duration of treatment before conception being 28 weeks (range 12-56 weeks) with a mean dose of carbimazole at conception of $13 \mathrm{mg}$ daily (range 5-15 mg daily). In five it was possible to discontinue carbimazole 12 to 32 weeks after conception (mean 19 weeks). One patient was not receiving drugs having been treated by subtotal thyroidectomy.

Serum long acting thyroid stimulator protector ${ }^{1}$ was measured in samples taken before conception (12 weeks or less), at 12 and 32 weeks after conception, and 12 to 24 weeks after delivery. Values were expressed as potencies determined by a three point bioassay and defined in units of an internal reference serum for long acting thyroid stimulator. One unit of the thyroid stimulator protector is defined as

\footnotetext{
Department of Medicine, Clinical Sciences Centre, Northern General Hospital, Sheffield S5 7AU

C A HARDISTY, MD, MRCP, lecturer

D S MUNRO, MD, FRCP, professor in medicine
}

Correspondence to: Dr C A Hardisty, Middlesbrough General Hospital, Ayresome Green Lane, Middlesbrough. the activity which blocks the binding of one unit of standard long acting thyroid stimulator to a human thyroid membrane preparation. ${ }^{1} \vec{\Rightarrow}$ In our hands the lower limit of detection for the thyroid stimulator $\stackrel{\text { ? }}{?}$ protector was 3 units internal standard $/ \mathrm{ml}$. Serial samples from an? individual patient were assayed together to minimise interassay variation. For valid calculations of potency the unknown response had $\frac{\bar{\omega}}{5}$ to be between two doses of standard. The validity of the assay method $\mathbb{Q}$ was well established from experience over five years when fewer than 1 in 20 four point bioassays showed significant deviation from parallel- $\infty$ ism or failed to show a significant regression. The mean index of $\vec{O}$ precision $(\lambda)$ for the bioassay was $0 \cdot 20$.

\section{Results}

The figure shows the activities of serum long acting thyroid ${ }_{\infty}^{\infty}$ stimulator protector in the nine pregnancies. In two patients treated 0 with carbimazole throughout pregnancy activities of the thyroid stimulator protector persisted and there was evidence of continuing thyroid overactivity. At delivery the activity of the protector in the

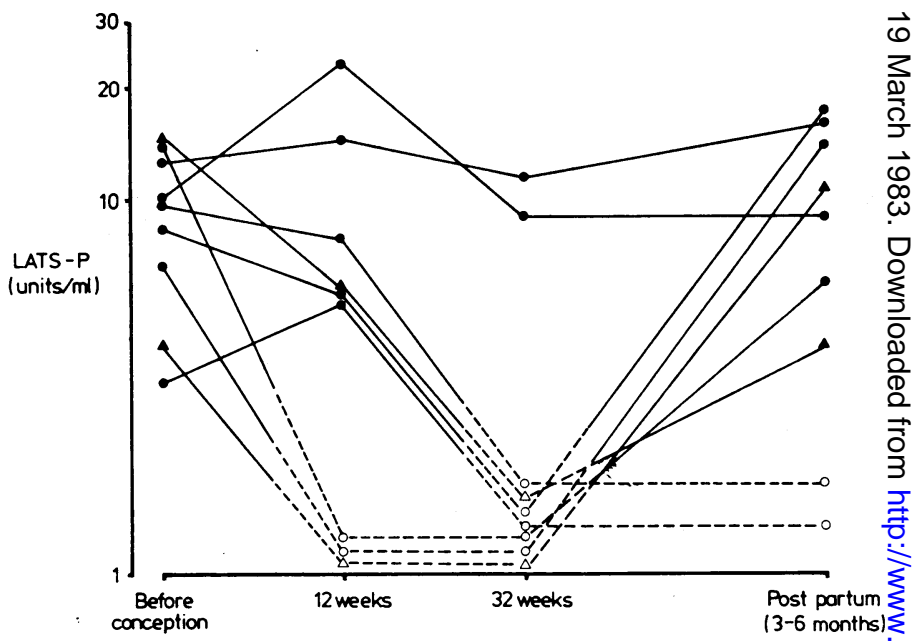

Activities of serum long acting thyroid stimulator protector (LATS-P) in nine pregnancies complicated by Graves' disease. Two pregnancies studied? in patient previously successfully treated by subtotal thyroidectomy $(\boldsymbol{\Delta})$ and seven in patients being treated with carbimazole $(\Theta)$. Lower limit of sensitivity of assay 3 units international standard $/ \mathrm{ml} . \triangle O=$ No activity detected.

maternal circulation was not high enough to cause neonatal thyrotoxicosis, which, in our hands, usually occurs at activities of overo 20 units $/ \mathrm{ml}^{4}$ Five patients taking carbimazole remitted during pregnancy as activities of thyroid stimulator protector became undetect- $N$ able; carbimazole was safely discontinued. In three instances activities of the protector returned after delivery, and this was associated with clinical and biochemical relapse. In both pregnancies in the euthyroid patient previously treated by subtotal thyroidectomy activity of the protector disappeared but returned after delivery.

\section{Discussion}

For the first time we have shown that serum long acting $\varrho$ thyroid stimulator protector tends to disappear during pregnancye and may then reappear in the months after delivery. In those patients treated with carbimazole the clinical course tended to follow the changes in activity of the protector. This was mosto pronounced in three patients in whom remission during preg-? 
nancy was associated with disappearance of activity and relapse after delivery with its reappearance.

Carbimazole in high dosage ( $45 \mathrm{mg} /$ day) has an immunosuppressive effect on thyroid autoantibody values in Graves' disease. ${ }^{5}$ Though lower doses were used in our study, treatment with carbimazole may have been responsible for the loss of activity of the protector in five out of seven drug treated pregnancies, with its return in three patients after delivery being a rebound effect after withdrawal of the drug. Of 24 patients with toxic Graves' disease treated for one year using similar doses of carbimazole, however, long acting thyroid stimulator protector disappeared in only six. ${ }^{2}$

An alternative explanation is that pregnancy itself has a direct effect on the underlying process causing Graves' disease. Similar changes to those seen in this study have been observed in other thyroid autoantibody values during and after pregnancy associated with autoimmune thyroid disease. ${ }^{6}$ Some of the patients were hypothyroid and were therefore not taking carbimazole. No firm conclusion can be drawn from our findings in one euthyroid patient previously treated by subtotal thyroidectomy. Further studies are indicated in this group of patients with a history of Graves' disease who do not require drug treatment.
This work was supported by a grant from the Yorkshire Cancer Research Campaign.

\section{References}

${ }^{1}$ Dirmikis S. Some factors affecting the detection of long acting thyroid stimulator protector using the McKenzie bioassay. $\mathcal{F}$ Endocrinol $1974 ; 63$ : 427-38.

${ }^{2}$ Hardisty CA, Munro DS. Relationship between long acting thyroid stimulator protector and the course of Graves's disease. In: Stockiet JR, Nagataki S, eds. Thyroid research VIII. Melbourne: Australian Academy of Science, 1980:613-6.

${ }^{3}$ Man EB, Shaver BA, Cooke RE. Studies of children born to mothers with thyroid disease. Am $\mathcal{F}$ Obstet Gynecol 1958;75:728-41.

4 Munro DS, Dirmikis SM, Humphries H, Smith T, Broadhead GD. The role of thyroid stimulating immunoglobulins of Graves's disease in neonatal thyrotoxicosis. Br F Obstet Gynaecol 1978;85:837-43.

5 McGregor AM, Petersen MM, McLachlan SM, Rooke P, Smith BR, Hall R. Carbimazole and the autoimmune response in Graves' disease. $N$ Engl f Med 1980;303:302-7.

${ }^{6}$ Amino $\mathrm{N}$, Kuro $\mathrm{R}$, Tanizawa $\mathrm{O}$, et al. Change of serum antithyroid antibodies during and after pregnancy in autoimmune thyroid diseases. Clin Exp Immunol 1978;31:30-7.

(Accepted 21 fanuary 1983)

\title{
Glucose polymer supplementation of feeds for very low birthweight infants
}

\author{
A RAFFLES, G SCHILLER, P ERHARDT, M SILVERMAN
}

\begin{abstract}
The feeds of 14 very low birthweight infants (birth weight $<1500 \mathrm{~g}$ ) were supplemented with a glucose polymer (Caloreen) at the rate of $6 \mathrm{~g} / \mathrm{kg}$ body weight daily. Seven day periods of supplementation were alternated with seven day periods of normal feeding. Adding the glucose polymer significantly increased the rate of weight gain in these infants from $105 \mathrm{~g} /$ week to $140 \mathrm{~g} /$ week; growth rates in terms of length and head circumference were not affected. No adverse effects were noted.
\end{abstract}

Glucose polymer is a useful energy supplement for very low birthweight infants.

\section{Introduction}

The optimum method of nourishing infants of very low birth weight (less than $1500 \mathrm{~g}$ ) is controversial. ${ }^{1-3}$ Poor rates of growth are common despite maximum acceptable volumes of feed. There is concern that high fluid loads may contribute to morbidity in several ways, so that altering the composition of infant milk seems the simplest solution. Adding fat to the milk is of little advantage as it increases metabolic rate at the expense of

\section{Royal Postgraduate Medical School, Hammersmith Hospital,} London W12 OHS

A RAFFLES, DCH, MRCP, senior house officer in neonatal paediatrics G SCHILLER, MB, BS, senior house officer in neonatal paediatrics P ERHARDT, MRCP, senior house officer in neonatal paediatrics M SILVERMAN, MD, FRCP, consultant senior lecturer in paediatrics

Correspondence to: Dr $M$ Silverman. growth, ${ }^{4}$ while increasing the sugar content may lead to an excessively high osmolality with the risk of diarrhoea.

We have investigated the use of a glucose polymer (Caloreen) as a food supplement for infants of very low birth weight. This polymer exerts one fifth of the osmotic pressure of an isoenergetic solution of glucose. It is rapidly cleared from the stomach and absorbed in neonates ${ }^{6-9}$ and is converted to glucose intracellularly, giving a slow rise and sustained plateau of the plasma glucose concentration. There is no published information on the nutritional effects of this widely used substance in preterm infants.

\section{Patients and methods}

During the study babies weighing under $1500 \mathrm{~g}$, whether appropriate for gestational age or small for gestational age, were considered eligible for the trial provided that they were well and receiving all their nutrition by gastric tube. In particular, no infant was receiving phototherapy, oxygen, or intravenous fluids, was known to be suffering from infection, or had any condition requiring a restricted fluid regimen-for example, patent ductus arteriosus.

A crossover design was adopted. ${ }^{10}$ Glucose polymer supplementation periods of one week were alternated with control periods, the order of the first period being allocated at random. Fourteen infants completed at least two weeks of the study (table I). The total number of crossover periods was 40: four infants completed four crossover periods, four completed three periods, and six completed two periods.

TABLE I-Details of patients (values are means $\pm 1 S D ; n=14$ )

\begin{tabular}{cccc}
\hline $\begin{array}{c}\text { Gestational age } \\
\text { at birth (weeks) }\end{array}$ & $\begin{array}{c}\text { Postnatal age on } \\
\text { entry to study } \\
\text { (days) }\end{array}$ & Birth weight & $\begin{array}{c}\text { Weight on entry } \\
\text { to study (g) }\end{array}$ \\
\hline $28 \cdot 8 \pm 2 \cdot 1$ & $18 \cdot 1 \pm 10 \cdot 3$ & $969 \pm 123$ & $890 \pm 56$ \\
\hline
\end{tabular}

